To Cite: Lin, A. M. Y., \& Tong, A. (2008). Mobile cultures of migrant workers in Southern China: Informal literacies in the negotiation of (new) social relations of the new working women. Knowledge, Technology \& Policy, 21(2), 73-81.

\title{
Mobile Cultures of Migrant Workers in Southern China: \\ Informal Literacies in the Negotiation of (New) Social Relations of the New \\ Working Women
}

Authors: Angel Lin, Faculty of Education, University of Hong Kong

and Avin Tong, Freelance Writer and Researcher

Keywords: Mobile culture, SMS communication, informal literacies, migrant workers

\begin{abstract}
In this paper we analyze the data collected through in-depth interviews of migrant workers in Southern China about their mobile cultures. In particular, we focus on understanding the role that mobile cultures play in female workers' negotiation of their social and romantic relations, leisure space, and how these negotiations are directly or indirectly facilitated by development of informal literacies through their frequent SMS communicative practices. These will help us understand the lifestyle aspirations and life trajectories of the new young working women in China, who are experiencing the most rapid socioeconomic changes in society and negotiating their ways of life amidst much tension between old and new values governing lifestyle aspirations, familial and gender relations.
\end{abstract}




\section{Introduction}

Since the mid-1980s, many transnational corporations have rushed into mainland China for both its promise of large markets and low labor and production costs. Many rural Chinese people have also dreamed of living a city life through working in the new factories opened up by transnational corporations in urban areas, and in large numbers they have been moving from villages to urban cities, starting massive flows of rural-to-urban migration. These demographic flows have initiated chains of radical sociocultural changes in China in the past two decades (Gaetano and Jacka, 2004; Lin, 1997; Ma and Cheng, 2005; Solinger, 1999). Many scholars have conducted research on migrant workers to study their working environments, social networks and consumption practices. In this section, we will review some of the major studies to provide a general picture of the social lives of migrant workers in modern day China.

\subsection{Rural-to-urban migration: An individuating project driven by the desire for an urban middle-class life}

A new class of workers has arisen as China is evolving into an industrial powerhouse, and these workers desire to transform their rural lives by selling their hard labor in the newly formed industrial markets. In particular, rural women started to become important labor in factories and service sectors. Pun (2005) studies a group of women workers in China and finds that they are proud of their newly found urban identities. Through working in the factory, they seem to feel that they are at least active agents in living their own lives, and their wage-earning power seems to give them some sort of new power and freedom (Pun, 2005). In Ma's study (2006), those factory women are happy to get away from hometowns, so that they can marry later and develop their 
own career. This creates a desire for women to leave the village and escape to the urban city, to re-configure both women's identities and Chinese familial relations.

To these women the first step to realize one's dream to attain a modern life style is to enter the factory, although this also means immersing oneself in hard and tedious production work. Pun (2005: 9) describes the process of entering the factory at the beginning as actually a process of 'individuating the self', which makes someone realize that 'it had recourse to nobody but itself'. Although the work is simple, it is repetitive and monotonous, and everybody lives up to a strict schedule without much support from one another (Ma, 2006; Pun, 2005). Ma (2006) finds that workers cannot refuse to work overtime, and they need to comply with the machine's rhythm, and not with one's own biological clock. And consumption, for these workers, seems to be a way to gain temporary relief and to escape into fantasies about modern lifestyles and identities. We shall discuss more about this in the next section.

\subsection{Popularity of mobile phones and text-messaging: Markers of membership in modern communities}

The mobile cultures developed in China can be seen as one of the ways of acquiring a modern lifestyle through consumption. Law and Peng (2003, 2004, 2005) report on the widespread use of mobile phone and SMS among migrant workers in Southern China. According to statistics released by the Ministry of Information Industry, ${ }^{\mathrm{i}}$ the number of mobile phone subscribers reached 305 million in mid 2004. The national average penetration rate was 24 percent, with the Guangdong province having an above-national average penetration rate of around 60 percent. A recent survey of 
Law ${ }^{\mathrm{ii}}$ indicates that 64 percent of the migrant workers reported the use of mobile phones, and over 40 percent of them reported using it for text-messaging.

Migrant workers are among the lowest-income groups in Guangdong, largely taking up skilled and semi-skilled jobs in factories with monthly salaries ranging from 400 to 800 Yuans (US\$1 is approximately 8.23 Yuans) (Law and Peng, 2004). However, a migrant worker is willing to spend double or triple her/his monthly salary to purchase a mobile phone. The mobile phone seems to have become a symbol of social identity, and a marker of the keenly desired urban, cosmopolitan lifestyle. In particular, SMS has become very popular in China. In 2001, 18.9 billion messages were sent in Guangdong; in 2002, the number of messages increased strikingly to 90 billion, averaging 247 million a day. ${ }^{\text {iii }}$ In our study, most of the workers reported sending/receiving around 100-200 messages per month.

In the research literature, SMS has been reported to be an ideal tool for making social arrangements, recording appointments and addresses (Haig, 2002). Cartier et al. (2005: 9) use the term 'information have-less' to refer to a 'social, economic, and political category for millions of rural-to-urban migrants and laid-off workers who populate the vast gray zone of China's digital divide'. Those low-end digital technologies including SMS play an important role in enhancing labor mobility (both physical and social) and in the formation of 'translocal networks'. These technologies can perform critical informational functions, as tools of communication that keep migrants connected with family members, hometowns, and also new friends and contacts, which enables and facilitates information flows (Cartier et al., 2005). Law and Peng (2003, 2004, 2005) describe a number of both social and practical functions served by 
mobile phones and SMS; e.g., maintaining contact with family members in their home village, maintaining contact and friendship with kinsmen/women, and for purposes of dating and courtship.

After outlining the recent research literature above, in the next section, we shall introduce our interview study of a group of migrant workers in Southern China. Then important findings will be presented and their implications will be discussed. In the last part of the paper, directions for future studies will be explored.

\section{The present study}

The present study examines mobile cultures among migrant workers in the industrialized villages of Tangxia and Humen Towns of Dongguan in the Guangdong Province in Southern China. A total of 63 migrant workers, including 38 males and 25 females (pseudo-names are used to protect the privacy of informants), were interviewed between July 2004 and March 2005. The informants were young villagers from less-developed or poor provinces such as Hunan, Sichuan and Guangxi. Tangxia is one of the 32 towns under Dongguan's administration. It has 20 villages, with around 33,000 local residents and over 600,000 workers from outside the town. The factories there produce various products such as plastics, toys and garments.

Most of the informants have finished their junior-middle schooling and have a monthly salary between 400 to 800 Yuans. Some of them have spent seven or more years in Dongguan, while some have just been there for a year. In-depth semistructured individual and group interviews with the migrant workers were conducted to analyze their mobile consumption practices, as well as to understand their work life, 
leisure life and dilemmas/conflicts that they might experience in their everyday social relations. Most interviews were conducted in factories and some interviews were conducted in restaurants when the interviewers had dinner with migrant workers.

While both male and female workers were interviewed, our analysis in this paper will focus on understanding the role played by SMS in facilitating the female workers' development of informal literacies, which in turn facilitates their negotiation of new social and gender relations.

\section{Findings}

We shall divide our findings into two main sections. In the first section we discuss how these workers, limited as they seem to be in their formal literacy training, mobilize their linguistic resources with the help of SMS manuals (Lin, 2005) to become creative SMS writers. Then in section 3.2 we shall discuss the role that SMS plays in helping female workers to negotiate new kinds of virtual social relations.

\subsection{The creative SMS literacies of migrant workers: Mobilizing limited linguistic resources to craft out arty messages}

Emerging SMS literacies among workers with limited formal literacy skills

The existing statistics show that 18.9 billion messages were sent in 2001 in Guangdong but in 2002, the number of messages increased strikingly to 90 billion,

averaging 247 million a day. ${ }^{\text {iv }}$ In our study, most of the informants have come from villages and had little formal education (except for a very few of them, who have received college education). In doing their messaging, the migrant workers seem to 
need some language support. They report readily turning to SMS manuals (see Fig. 1), which are published as handy, smaller-than pocket-size booklets selling cheaply (e.g., 3 yuans) and circulating widely among these migrant workers (Lin, 2005). These manuals are organized as lists of numbered entries of short message texts placed under different topic headings (e.g., 'Humorous Sex Jokes', 'True Sentiment Confessions'). It seems to offer a textual supermarket of diverse linguistic and discursive resources as well as gender ideologies (Lin, 2005) made available to the migrant workers when they use SMS for purposes which are related to seeking (virtual) relationships and (virtual) experience of romantic/sexual pleasure and excitement.

Some workers report making efforts in creating their own messages, and they sometimes get inspiration from their friends' messages and also SMS manuals. For instance, Mr. Chow admits that he will copy some words/sentences from the SMS manuals, especially for romance topics. On the other hand, the boyfriend of Miss Fung usually copies passages from the newspaper (e.g., feature articles), which are often related to romance and jokes. Research on intertextuality shows that literacy artifacts and images invoke social practices from a range of different social contexts (Maybin, 2000). In our study, the messages provided in SMS manuals seem to serve as important sources of references to SMS users in their everyday texting practices.

Although SMS manuals are quite popular among migrant workers, some of our informants claim that they do not rely on manuals and prefer creating messages themselves. Miss Fung, for instance, criticizes those 'typical examples' in SMS manuals as 'not interesting'. Another informant, Miss Mui, insists that she just reads 
SMS manuals but never copies messages from them, 'I seldom send out those messages, (what I send out) are all my own words.' One of the male workers, Mr. Yu, says, 'Those (messages) written on the manuals are already outdated. Those messages that come out from one's mind are the best...think and create a message; it's a kind of training.'

Miss Mui has bought a few SMS manuals, which teach people how to write different types of messages such as jokes and interesting stories. But she insists that she uses the guide very occasionally. She describes some tactics in 're-creating' messages received/learnt from the SMS manuals: 'I seldom copy every word of it; I just take it as a reference...change it to make it better...won't forward it without changing a word.' She thought that the 're-creation' process is rather easy, as she puts it:

It's easy for me to send (a message), and it's easy for me to type, very fast. Even when others sent me a copied message, I will change it a bit when I send it to others; add some more or delete some parts...just add some new words in the front or at the back, or take away some of it.

Researchers in informal literacy believe that the schooling tradition of cultivating formal literacy seems to downplay the role played by the indigenous, informal linguistic and creative resources of people (Street, 1993). In our study, it is interesting to find that workers with relatively limited formal education sometimes display great creativity when they compose mobile messages. For instance, A male worker, Mr. Ho, says, 'Some of my friends enjoy writing poems, and sometimes (they) write good wishes and send (them) to me.' Writing a poem is not an easy task for a factory worker, as most of them only have limited schooling experiences. In fact, factory 
work does not involve literacy work and there is no chance for migrant workers to develop their literacy skills. SMS thus provides them with a valuable medium and opportunity for practicing their informal, everyday literacies.

Literacy learning and uses are actually integrated into everyday activities (Hamilton, 2006). Ethnographic studies of everyday settings (Barton and Hamilton, 1998) have explored the relationship between the lived experience of literacy and learning. One of the important notions of everyday literacy research is to see literacy as a social practice (e.g., choosing verses in greetings cards exchanged, cherishing letters and autographs). We thus need to look into the diverse ways in which literacy is acquired, not just in school settings and by children, but also in everyday life and by adults. In our study, it seems that through creating and re-creating different types of SMS messages, it is possible for migrant workers to acquire and practise literacy skills informally in their everyday life.

\section{SMS literacies in the negotiation of (new) gender relations}

Men and women seem to express themselves differently, as revealed in their practices of using mobile phones/SMS. As reported in Law and Peng (2003, 2005), many male workers claim that they would prefer making voice calls to sending messages, while female workers prefer sending messages. This point is also made by our female informant, Miss Fung, as her boyfriend seems to have no interest in sending SMS. She recalls some unhappy experiences, 'If I send him messages, ask him what he is doing, he will reply: "I am busy"...every time he says he is busy after chatting for a few sentences... Every time it's he who uses "busy" as a reason for closing the conversation.' She also prefers more expressive writing styles instead of instrumental 
and practical ones. She says, 'He never seriously sends me three words saying "I miss you", he never sends it...I know he misses me...but he never sends (me) those three words.'

However, some male informants are actually willing and eager to use this new medium of communication to express themselves and to find themselves a (virtual) social life. A male informant, Mr. Ho, admits that SMS has become an important part of his leisure life, and he will feel depressed if no one sends him any SMS. 'If I haven't received any messages for a few days, I will feel a bit unhappy in my heart. (I) will have a feeling of being isolated.' A similar remark is made by Mr. Au, 'If I haven't received any SMS for two or three days, I will ask myself: how come I haven't received any SMS?' Besides, some male workers have become heavy users of SMS. A female worker, Miss Lau, recalls, 'I know one boy who is fond of sending SMS; each time (the message) he sent me contains two hundred to three hundred words.' These new attitudes and behavior of some male workers seem to deviate from the stereotypical image of Chinese men, who are often thought to be few in words especially when it comes to social writing.

In some cases, male workers make use of SMS in settling arguments with girlfriends, and some of them, like Mr. Kok, use SMS for dating and courtship in the initial stage, as they report being able to express their feelings more freely in a textual world. As Zubair (2001) suggests, we should look at literacy practices as part of the broader gender relations situated in the larger social and cultural contexts. In our case, informants reveal both confinement to certain gender stereotypes (e.g., writing styles), and some breakthroughs from some traditional expectations (e.g., efforts of some 
males in creating messages, and their high frequency of sending long messages). Our preliminary interview data thus point to the possibility that some male workers are developing and using their SMS literacy skills to negotiate and work on achieving more satisfying social and gender relations. In the next section, we shall discuss, in particular, how female workers have capitalized on their newly developed informal SMS literacy skills to acquire more social capital.

\subsection{Seeking and constructing virtual romance through SMS literacy practices}

Acquiring social capital: Making oneself attractive in the virtual space

Since the mid-1980s, descriptions of literacy as a form of cultural capital have become an integral part of the debates over social effects (Bourdieu, 1991; CookGumperz, 1986). Boudieu (1984) has theorized different types of capital in different social fields. Cultural capital describes 'the sum total of durable knowledges and practices, disursive and material resources acquired by individuals as they develop across their life trajectories'; while social capital refers to the 'direct access to social and cultural institutions and organizations' (Luke, 1995: 16). In our study, migrant workers actually enter a complexity of social fields, and involve in complex interrelationships between cultural and social capital through their use of mobile phones/text-messaging.

Mobile phones provide an on-line service for people to meet new people in the cyberspace. Workers are always receiving messages from strangers hoping to make romantic contact with others through mobile phones (Law and Peng, 2003). Some migrant workers choose to chat with strangers (especially those of the opposite-sex) using this online service provided by the mobile phone service. There is a popular 
network called 'Mobile Fantasy Network' organized to help men and women find 'good friends', and in most cases 'lovers'. To develop such kind of intimate relationship, cultural capital is required to make oneself more appealing and sociable. The most illustrative case is that of Miss Fung, who started participating in the chat room a few years ago, and has now become very 'professional' in searching 'suitable' male virtual partners. She likes using different names, such as 'Apple,' 'Ice,' and 'Windie' to $\log$ on to different chat rooms. She spends quite a lot of time on creating beautiful 'names' for herself in the chat room, which involves certain literacy skills. She analyzes her naming practices in this way, 'People like pretty girls. I have once been called Ching Chi ('Virtuous Girl'), and also Han Bing ('Cool Ice').

Miss Fung shows her social skills and SMS expertise by readily providing others with tips on how to create impressive and favorable identities. For example, she teaches male players (in the SMS chat room) to claim themselves as young men with a cheerful character and handsome appearance so as to attract female netizens. Here is the personal experience of Miss Fung, which points to her linguistic tactics in constructing attractive online identities:

Men usually claim to be twenty-something, it is because if they are already in their thirties and still (need to) go online, then they must have some problems. Others don't want to chat (with you)... it will fail if you are too honest. (People) want to kill loneliness when (they) participate in online chatting, and if you are too boring, then I prefer not to chat (with you) instead...sometimes I ask others, are you handsome? When he says he is not handsome, then I will say sorry (to him), I don't want to chat with you. 
Luke (2005) proposes the 'personal growth hypothesis', which links the acquisition of literacy and series of consequences. He proposes that individual 'voice' and expression will lead to psychological development. This means that literate success is 'a matter of expressing individual difference, establishing self-esteem, identity and "choice", (Luke, 2005: 9). The case of Miss Fung illustrates the discursive tactics of building an impressive self-identity by utilizing the informal SMS literacy skills that she has developed. The beautiful names and communication tactics are highly rewarding emotionally, and they also hold a promise of meeting new friends (in particular, friends of the opposite sex). In theoretical terms, she is converting her cultural capital (i.e., informal SMS literacy skills) into social capital (e.g., social networks) in the process of text-messaging.

\section{Fantasies woven around romantic and ambivalent relations}

Ellwood-Clayton (2003) finds that some Filipinos are restructuring amorous lived relationships and creating virtual ones through text communication, and so textmessaging seems to have induced changes in the traditional courtship practices among young people. SMS seems to provide a space for emerging amorous feelings, romance, and it is found to instill personal bravery among its users. In particular, women are encouraged to speak out their feelings and take more initiative in the textual world. Though many informants claim that they are not purposefully searching for romance, most of them admit that it is much more fun to chat with netizens of the opposite-sex.

This kind of ambivalent relationship and virtual romance provide the workers with daydreams and fantasy, which can be useful in consoling their lonely spirits. Gossip, 
jokes and laughter centered on love and sex helped the workers to cope with the tedious and difficult factory life, as a weapon against the alienation of work (Pun, 2005). Some women adopt new literacy genres to open up new worlds and identities, to overcome their oppressive situations. In our study, some female workers try to attract strangers of the opposite sex by creating beautiful names and applying communication tactics, and in return they receive some sweet phrases that they are longing for. It is similar to the kind of 'fantasy literacy' suggested by Luke and Carrington (2001: 17), which aims at 'a suspension of position in the social fields and scapes of globalisation and a psychic disengagement with flows'. It enables the SMS users to read and write out of local place and space, to enjoy romance with complete strangers beyond geographical boundaries.

\section{Negotiation with love and gender relations in reality}

This kind of pleasure obtained from virtual romance fulfills workers' (especially young women's) desires for romantic love. According to what our informants told us, some of our workers are dissatisfied with their love life in reality, for example, having communication problems with their lovers. As Miss Fung points out in the above examples, she enjoys the 'sweet words and honeyed phrases' that are 'absent in reality'. In fact, constructing virtual romance may have an influence on real life love relations. In the case of Miss Fung, her boyfriend dislikes her spending so much time and money on sending SMS/chatting with other men. Miss Fung recalls his words:

'He told me, I dislike you chatting on the net. I ask why, he said it particularly hurt a relationship...He believes that all I heard online are sweet words and honeyed phrases, which cannot be heard in real life...it is because things on 
the net are so insincere; and (they) hurt our relationship. But sometimes when I feel annoyed alone, I will want to chat with someone.'

Mediated communication always underlies specific restrictions of coding. Walter (1996) suggests the term 'hyperpersonal interaction', which means that mediated communication is more desirable as compared to face-to-face interaction (Hoflich, 2003). This kind of 'hyperpersonal interaction' enables migrant workers to develop ambivalent and even intimate 'online' relations with netizens, which seem to be more pleasurable and enjoyable then the 'offline' love life. Nevertheless, as indicated in the case of Miss Fung, virtual romance (originating from the online world and then extended to other communicative means, like SMS in this case) satisfies the desires for being loved in the workers' hearts but also creates communicative problems (e.g. wrong expectations, frequent quarrels) between 'real lovers' in reality.

One important phenomenon we see here is the changing life aspirations, both in career and love, of the young women in China. Nowadays many young Chinese rural women no longer stay at home and wait for a matchmaker to decide their fate; instead many of them are encouraged to go out and leave their villages, look for their own love and life (Pun, 2005). In our study, it is found that women workers often have more job opportunities than men, and they even make more money than their male counterparts. Our informant, Miss Hang, points out, 'Male work is more difficult (to find) than female work right from the beginning...work outside always prefers female labor.' The rising social status and increasing economic power of women grant them more freedom in marriage, and also in pursing one's life goal. They are both eager and confident to choose a better partner whom they really love. 
These young working women will have higher expectations on men, as their qualities have improved and their social circles have enlarged. Miss Sang, a factory owner, believes that it is difficult for a female worker to find a suitable male partner in the workplace. She says, 'If you ask our (female) workers to choose a man in the factory, (they) absolutely cannot choose one. These men are poor and not good-looking either.' With the experience of working in the city and exposure to popular culture, liberating messages found in SMS manuals like 'developing one's own career', 'finding true love' and 'enjoying one's own life' have become mottos for these modern working women with new aspirations.

\section{Conclusion: Alternatives for women-the potential of literacy as empowerment}

In Southern China, compressed and multi-layered modernity means the pluralization of life choices in which various forms of individuality can be imagined and practiced (Ma and Cheng, 2005). Migrant workers, who have been accustomed to a relatively stable set of practices of early marriage in the villages, are now thrown into a fluid set of discourses about dating, love, romance, choices, and desires. As Ma and Cheng (2005) point out, 'In their de-traditionalized and de-territorialized lifeworlds, migrant workers find themselves in a ruptured discursive space where new intimate experiences require new hybrid vocabularies to express themselves'. In our interviews, we found that the young female migrant workers need to seek fantasies and pleasures in their leisure life-ambivalent relations and virtual romance, strengthened or expanded social relations - to balance the alienating and individuating 
factory life, as well as to live a completely new woman's life as compared to the old times in rural areas.

In this modern, urban, alienating workplace, women have been presented as the major victims in many academic discourses. For instance, Pun (2005) is rather pessimistic in concluding about the future life of the female migrant workers, as she finds them under multiple and inescapable oppressions. However, some people believe that literacy can empower, through collective actions and enhancement of individual capacity (Rockhill, 1993). We propose that literacy is highly related to power relations and can offer alternatives in people's lives. In our study, through the use of mobile phone and SMS, these migrant workers in Southern China search for virtual pleasure and emotional release. In particular, women workers seem to have developed a desire to seek pleasurable leisure lifestyles outside of the workplace. Informal literacies are both acquired and strengthened in their frequent SMS communication practices, which involve different dimensions of competencies ranging from technological skills to creative writing, and to communicative tactics in fashioning an attractive self on the net.

The study of Rockhill (1993) demonstrates how women talk about their longing for literacy. Robinson-Pant (2001) argues that women themselves tend to associate literacy with a new identity, and want to demonstrate their new roles as 'literate' women. In this study, it also seems that informal literacy practices have become essential tools in dealing with the urban city discourses, and to pursue a 'modern life' of one's desire even with very limited means. Our female informants have already shown their dreams/desires to escape from the patriarchal familial relations in the 
rural village; they dream of developing a new urban identity together with new, modern womanhood. It seems that these factory women have acquired new attitudes toward love, marriage and members of the opposite sex. These attitudes seem to be very different from the previous values of traditional Chinese women. Informal literacy seems to offer them some cultural capital to engage in different communicative practices (e.g., composing poetic SMS messages, fashioning attractive poetic names for oneself), which may reward them with both a sense of agency and with social capital in finding new pleasurable social relationships, even though these might be transient, virtual ones.

Our research also leads us to a new approach to studying mobile communication. This approach sees mobile communication, text-messaging in particular, as a social practice involving everyday literacies. The study of everyday literacy practices draws attention to the texts of everyday life and the texts of private and personal life, just like some of the intimate text messages found in our study. It seems that people can utilize and improve their literacy skills (e.g., technological skills, writing and reading skills) through text-messaging, while strengthening old relations and establishing new (virtual) connections. This reminds us to extend the scope of 'literacy' beyond the school setting, and to study new media literacy practices embedded in everyday social interactions.

Further studies can research on other informal literacy practices, to uncover their meanings and impact on people's lives situated in specific sociocultural contexts. The different cultural and social practices of male and female workers can also be studied, to help them explore more about their own needs and situations, and to enable them to 
build more satisfying gender relations in the rapidly changing Chinese society. Much more work, both of the research and social activist kinds, would seem to be needed in the near future.

[Insert Fig. 1 about here]

Fig. 1. SMS Manuals Popular Among Migrant Workers in Southern China 


\section{Acknowledgements:}

The authors are indebted to Patrick Law, Wang Ting, Yang Ke, Liu Xiaojing and Peng Yinni for their valuable work in collecting the interview data for this study. Special thanks also go to the anonymous reviewers for their very useful comments and suggestions.

\section{References}

Baym, N. K. (1998) The emergence of on-line community. In S. Jones (Ed.), Cybersociety 2.0: Revisiting computer-mediated communication and community (pp. 35-68). Thousand Oaks, California: Sage.

Barton, D. \& Hamilton, M. (1998). Local literacies: Reading and writing in one community. London: Routledge.

Bourdieu, P. (1986). The forms of capital. In J.G. Richardson (Ed.), Handbook of theory and research for the sociology of education (pp. 241-258). New York: Greenwood Press.

Bourdieu, P. (1991). Language and symbolic power. (J.B. Thompson, Ed.; G. Raymond and M. Adamson, Trans.). Cambridge: Polity Press.

Bourdieu, P. (1993). The field of cultural production: Essays on art and literature. (Randal Johnson, Trans. \& Intro.). New York: Columbia University Press.

Cartier, C., Castells, M. \& Qiu, J. L. (2005). The information have-less: Inequality, mobility, and translocal networks in Chinese cities. Studies in Comparative International Development, 42(2): 9-34.

Cook-Gumperz, J. (1986). Literacy and schooling: An unchanging equation?. In J. Cook-Gumperz (Ed.), The social construction of literacy (pp. 16-44). Cambridge: Cambridge University Press. 
Ellwood-Clayton, B. (2003). Virtual strangers: Young love and texting in the Filipino Archipelago of cyberspace. In K. Nyiri (Ed.), Communications in the 21st Century. Mobile democracy: Essays on society, self and politics (pp. 225-239). Hungary: Passagen Verlag.

Fernback, J. (1999). There is a there there: Notes toward a definition of cybercommunity. In S. Jones (Ed.), Doing Internet research: Critical issues and methods for examining the Net (pp. 203-220). London: Sage.

Gaetano, A. and Jacka, T. (Eds.) (2004). On the move: Women in rural-to-urban migration in contemporary China. New York: Columbia University Press.

Haig, M. (2002). Mobile marketing: The message revolution: A cracking insight into how to really get personal with your customers. New York: Kogan Page.

Hamilton, M. (2006). Understanding the everyday : Adult lives, literacies, and informal learning. In A. Mckeough, L. M. Philips, V. Timmons and J. L . Lupart (Eds.), Understanding literacy development: A global view (pp. 137-152). Mahwah, N.J.: Lawrence Erlbaum Associates.

Hoflich, J. R. (2003). Part of two frames: Mobile communication and the situational arrangement of communicative behaviour. In K. Nyiri (Ed.), Communications in the 21st Century. Mobile democracy: Essays on society, self and politics (pp. 3553). Hungary: Passagen Verlag.

Law, P. and Peng, Y. (2003). Cellphone, Internet and the SARS epidemic. Unpublished manuscript. Law, P. and Peng, Y. Cellphone, Internet, and the SARS epidemic. Proceedings of the International Workshop on Mobile Technologies and Health: Benefits and Risks. (Udine, Italy, 2004), 7-8.

Law, P. and Peng, Y. (2004). The use of cellphones amongst migrant workers in southern China. Unpublished manuscript. Law, P. and Peng, Y. (2004). The use 
of cellphones among migrant workers in southern China. Proceedings of the Conference of Mobile Communication and Social Change, 18th-19th October, Seoul, Korea.

Law, P. and Peng, Y. (2005). Cellphones and the social lives of migrant workers in southern China. Unpublished manuscript. Law, P. (2007). Cellphones and the social lives of migrant workers in Southern China. In Pertierra, R. (Ed.), The Social construction and usage of communication technologies: Asian and European experiences, (pp.126-42). Quezon City: University of the Philippines Press.

Lin, A. (2005). Romance and sexual ideologies in SMS manuals circulating among migrant workers in southern China. Paper presented at the Mobile Communication Conference, 7-8 June 2005. City University of Hong Kong, Hong Kong.

Lin, G. (1997). Red capitalism in southern China: Growth and development of the Pearl River Delta. Vancouver: University of British Columbia Press.

Luke, A. and V., Carrington. (2001). Globalization, literacy, curriculum practice. In R. Fisher, M. Lewis and G. Brooks (Eds.). Language and literacy in action (pp. 231-250). London: Routledge/Falmer.

Ma, E. (2006). Jiu ba gong chang: Nan zhongguo cheng shi wen hua yan jiu (Chinese). Nanjing: Jiangsu ren min chu ban she.

Ma, E. and Cheng, H. (2005). Naked bodies: experimenting with intimate relations among migrant workers in south China. International Journal of Cultural Studies, $8(3), 307-328$.

Pun, N. (2005). Made in China: Women factory workers in a global workplace. Durham/Hong Kong: Duke University Press/Hong Kong University Press. 
Robinson-Pant, A. (2001). Women's literacy and health: Can an ethnographic researcher find the links?. In B. Street (Ed.), Literacy and development: ethnographic perspectives (pp. 152-170). London and New York: Routledge.

Rockhill, K. (1993). Gender, language and the politics of literacy. In B. Street (Ed.), Cross-cultural approaches to literacy (pp. 156-175). Cambridge: Cambridge University Press.

Solinger, D. (1999). Contesting citizenship in urban China: Peasant migrants, the state, and the logic of the market. Berkeley: University of California Press.

Street, B. (Ed.). (1993). Cross-cultural approaches to literacy. Cambridge: Cambridge University Press.

Walter, J. B. (1996). Computer-mediated communication: Impersonal, interpersonal and hyperpersonal interaction. Communication Research 23, 3-43.

Zubair, S. (2001). Literacies, gender and power in rural Pakistan. In B. Street (Ed.) Literacy and development: Ethnographic perspectives (pp.188-204). London and New York: Routledge.

\footnotetext{
${ }^{\mathrm{i}}$ See http://www.mii.gov.cn.

ii An initial figure obtained from an unpublished project of Law on the situation of migrant workers in China

iii 'Thumb Economy’ Earned 9 Billion, Mingpao Daily (2003, September 14), B6.

iv ‘Thumb Economy’ Earned 9 Billion, Mingpao Daily (2003, September 14), B6.
} 